\title{
An experimental protocol for the establishment of dogs with long-term cellular immune reactions to Leishmania antigens
}

\author{
Márcia Cristina Aquino Teixeira' ${ }^{1 /}$, Geraldo Gileno de Sá Oliveira ${ }^{2}$, Patrícia Oliveira Meira Santos ${ }^{2,3}$, \\ Thiago Campanharo Bahiense, ${ }^{1,2}$, Virginia Maria Goes da Silva ${ }^{2,4}$, Márcio Silva Rodrigues², \\ Daniela Farias Larangeira ${ }^{1,2}$, Washington Luis Conrado dos-Santos ${ }^{2,5}$, \\ Lain Carlos Pontes-de-Carvalho ${ }^{2,5}$
}

\author{
${ }^{1}$ Universidade Federal da Bahia, Salvador, BA, Brasil ${ }^{2}$ Centro de Pesquisa Gonçalo Moniz-Fiocruz, Salvador, BA, Brasil \\ ${ }^{3}$ Universidade Federal do Ceará, Fortaleza, CE, Brasil ${ }^{4}$ Universidade Estadual do Sudoeste da Bahia, Jequié, BA, Brasil \\ ${ }^{5}$ Escola Bahiana de Medicina e Saúde Publica, Salvador, BA, Brasil
}

\begin{abstract}
Domestic dogs are considered to be the main reservoirs of zoonotic visceral leishmaniasis. In this work, we evaluated a protocol to induce Leishmania infantum/Leishmania chagasi-specific cellular and humoral immune responses in dogs, which consisted of two injections of Leishmania promastigote lysate followed by a subcutaneous inoculation of viable promastigotes. The primary objective was to establish a canine experimental model to provide positive controls for testing immune responses to Leishmania in laboratory conditions. After inoculation of viable promastigotes, specific proliferative responses of peripheral blood mononuclear cells (PBMCs) to either Leishmania lysate or recombinant proteins, the in vitro production of interferon- $\gamma$ by antigen-stimulated PBMCs and a significant increase in circulating levels of anti-Leishmania antibodies were observed. The immunized dogs also displayed positive delayed-type hypersensitivity reactions to Leishmania crude antigens and to purified recombinant proteins. An important finding that supports the suitability of the dogs as positive controls is that they remained healthy for the entire observation period, i.e., more than seven years after infection. Following the Leishmania antigen lysate injections, the infection of dogs by the subcutaneous route appears to induce a sustained cellular immune response, leading to an asymptomatic infection. This provides a useful model for both the selection of immunogenic Leishmania antigens and for immunobiological studies on their possible immunoprotective activities.
\end{abstract}

Key words: Leishmania infantum - Leishmania chagasi - dogs - immunization - cellular immune response

Visceral leishmaniasis (VL) is increasingly becoming a major public health concern due to its dispersal to previously non-endemic rural areas, the emergence of disease foci in urban areas and, more recently, its opportunistic association with human immunodeficiency virus infection (Mestre \& Fontes 2007, Alvar et al. 2008, Maroli et al. 2008, Cerbino Neto et al. 2009). In the New World, VL is caused by Leishmania chagasi, which is believed to be identical to Leishmania infantum (reviewed by Maurício et al. 2000). Therefore, in the present paper, the parasite will be referred to as $L$. infantum.

Several pieces of evidence have been reported that support a role for dogs as domestic reservoirs of $L$. infantum: first, Leishmania-infected dogs are frequently present in domestic and peridomestic environments in VL-endemic areas, second, dogs from endemic areas exhibit high seropositivity rates and third, sick dogs suffer from intense skin parasitism, which, theoretically, more readily exposes Leishmania to the sand fly (Travi et al. 2001, Mestre \& Fontes 2007, Maroli et al. 2008, Verçosa

Financial support: PRONEX, PADCT, RENORBIO, CNPq, INOVABIO, CADCT/FAPESB

+ Corresponding author: marciat@ufba.br

Received 15 August 2010

Accepted 1 December 2010 et al. 2008). The main control measures adopted in Brazil are vector control using insecticides, treatment of human cases and serological surveys, followed by culling of seropositive canines. However, the massive elimination of dogs between 1990-1997 did not reduce the incidence of the human disease (Costa \& Vieira 2001), indicating that the implementation of this measure alone was ineffective. Accordingly, the World Health Organization considers the deployment of an effective vaccine to be an important alternative for the control of leishmaniasis (Desjeux 2002).

Studies on natural and experimental L. infantum infections in dogs indicate that many animals develop asymptomatic infections, probably due to an efficient cellular immune response against the parasite (Cabral et al. 1992, Pinelli et al. 1994, Dye 1996, Dos-Santos et al. 2008), suggesting that a canine vaccine is feasible. In fact, the availability of purified and recombinant Leishmania proteins, together with the increasing understanding of the immunological mechanisms involved in the control of leishmaniasis, have enhanced studies of antiLeishmania vaccines in the canine model (Borja-Cabrera et al. 2002, 2008, 2010, Fujiwara et al. 2005, Moreno et al. 2007, Rodríguez-Cortés et al. 2007b, de Lima et al. 2010). However, the number of Leishmania immunization/infection studies in canine models is still limited in comparison to those reported in murine models.

To assess the efficacy of a vaccine candidate against canine leishmaniasis, it is desirable and/or necessary to 
monitor and quantify certain biological parameters, such as (i) the development of clinical signs of disease, (ii) the levels and isotypic profiles of anti-Leishmania antibodies, (iii) the presence, nature and intensity of antigenspecific proliferative responses and/or the production of cytokines in antigen-stimulated peripheral blood mononuclear cells (PBMCs), (iv) the presence of skin hypersensitivity in response to inoculated antigens and (v) the determination of the capacity of immunized dogs to transmit the parasites to sand flies. Concerning the measurement of these parameters, one of the major problems in studying canine immune responses to Leishmania antigens is the lack of a convenient source of antigen-specific canine lymphocytes that may be used as positive controls in biological assays for cell-mediated immunity, which appears to be protective against Leishmania infection in dogs (Leandro et al. 2001, Rodrigues et al. 2007, Araújo et al. 2009, Bourdoiseau et al. 2009). In dogs, as in human beings, cell-mediated immune responses are assessed either by injecting adequately diluted antigenic preparations into the skin and subsequently measuring a delayed-type hypersensitivity response or by stimulating PBMCs with antigens in vitro and measuring cell proliferation or cytokine production (Santos-Gomes et al. 2000, Chamizo et al. 2005, Carrillo et al. 2008, DosSantos et al. 2008, Bourdoiseau et al. 2009). Immortalized T cell lines (Barsov 2009, Bartelt et al. 2009), which are exhaustively selected in vitro for antigen reactivity, do not represent an ideal substitute for freshly-collected PBMCs as control cells for in vitro immunological reactions because it is difficult to guarantee that the cell lines reflect the unselected PBMC population, in terms of both their repertoire of antigen recognition and their adaptation to in vitro conditions. It is operationally complex to obtain Leishmania-infected asymptomatic dogs in endemic areas to serve as positive controls for cellmediated immune responses and there is no guarantee that the asymptomatic dogs will not become sick with the passage of time.

With the aim of obtaining a source of Leishmania antigen-responder canine lymphocytes, L. infantumspecific cellular and humoral immune responses were evaluated in vivo and in vitro at various time points of an immunization protocol (after injection of a Leishmania promastigote lysate and the subsequent inoculation of viable promastigotes). The results indicate that, following the immunization with parasite crude antigens, the induction of a sub-clinical $L$. infantum infection is more efficient than immunization with parasite antigens alone in terms of eliciting both humoral and cellular immune responses against either native or recombinant $L$. infantum antigens.

\section{SUBJECTS, MATERIALS AND METHODS}

Parasite and antigens - The Leishmania used in this study was isolated from the bone marrow of a human patient and identified as L. infantum (MHOM/BR2000/ Merivaldo2 strain). The parasite was maintained by passage in golden hamsters and cultivation in Schneider's Drosophila medium (Sigma Aldrich, St. Louis, MO, USA), supplemented with $20 \%$ foetal bovine serum
(FBS) (Gibco BRL, Gaithersburg, MD, USA), at $22^{\circ} \mathrm{C}$ and at $\mathrm{pH}$ 7.2. For the immunization of dogs and the detection of antibodies in serum samples by enzyme linked immunosorbent assay (ELISA), promastigotes in the stationary phase of growth were washed by centrifugation with $0.15 \mathrm{M}$ phosphate-buffered saline (PBS), $\mathrm{pH} 7.2$ and lysed by ultrasonic exposure (5 cycles of $30 \mathrm{~s}$ at $80 \%$ output with intermediate cooling cycles of $1 \mathrm{~min}$ ) (Branson Sonifier 450W, Branson Instruments, Danbury, CT, USA). The lysate was stored at $-20^{\circ} \mathrm{C}$ until use. The Lci1 (an Hsp70 heat shock protein polypeptide segment) and Lci2 (a kinesin polypeptide segment) L. infantum amastigote recombinant antigens (patent PI0900961-2, INPI, Brazil, 2009), encoded by plasmids constructed with $L$. infantum amastigote cDNA, were expressed in Escherichia coli and purified either by an inclusion body (insoluble aggregate of over-expressed proteins) isolation protocol (Babu et al. 2000) or by immobilized metal-ion affinity chromatography using nickel-chelating Sepharose Fast Flow columns (GE Healthcare, Uppsala, Sweden), according to the directions of Jedrzejas et al. (1998). The degree of purity of the recombinant antigens was analyzed by $10 \%$ polyacrylamide gel electrophoresis in the presence of sodium dodecyl sulphate, followed by Coomassie blue staining, as described previously (Laemmli 1970). The protein content of each antigen preparation was determined by protein reaction with fluorescamine (Lorenzen \& Kennedy 1993). For the lymphoproliferative assays, crude and purified antigens were dialysed against Roswell Park Memorial Institute (RPMI) medium and sterilised by gamma-ray irradiation.

Animals and experimental design - Twenty-nine mixed-bred dogs, two to four-years old, were obtained from the Salvador City Zoonosis Control Center and kept in a kennel at the Gonçalo Moniz Research Center, Oswaldo Cruz Foundation (Fiocruz), Salvador, Bahia, with daily recreation in a dedicated area. All the dogs were examined and treated when necessary for anaemia, intestinal parasitosis and ectoparasitosis and all received routine vaccination against leptospirosis, distemper, adenoviruses, parainfluenza and parvoviruses during an acclimatization period. All the dogs were confirmed to be free of Leishmania based on the absence of parasites by microscopic examination of spleen aspirate cultures and the absence of detectable specific antibodies by ELISA (detailed in Determination of anti-Leishmania antibody levels) and immunofluorescence, as described by Paranhos-Silva et al. (1996). Periodic surveys of the kennel for the presence of vectors of Leishmania, performed with the use of light traps, produced negative results. A group of four animals (dogs 1-4) was subjected to the following subcutaneous immunization protocol: (i) two biweekly injections of a lysate derived from $10^{8}$ Leishmania promastigotes in incomplete Freund adjuvant and (ii) an inoculation of $10^{8}$ live stationary-phase Leishmania promastigotes four weeks later. A control group of three animals (dogs 5-7) was treated at the same time intervals with saline and adjuvant and then saline alone instead of viable promastigotes. For the assessment of lymphoproliferative responses and IFN- $\gamma$ production af- 
ter seven and four years of immunization, respectively, other control groups consisted of untreated animals and animals injected subcutaneously with $200 \mu \mathrm{g}$ of the Lci1 or Lci2 L. infantum recombinant antigens (Santos 2007). Cellular and humoral immune responses against Leishmania were evaluated three weeks after the second lysate injection, six and 45 weeks after the live parasite inoculation and four-seven years after the immunization. Spleen aspirates were collected every three months for the first two years after the inoculation of viable promastigotes and were cultured in biphasic medium (blood agar-Schneider's medium). The animals were clinically monitored by a veterinarian throughout the experiment, which was conducted in accordance with the Fiocruz guidelines for the use of experimental animals.

Determination of anti-Leishmania antibody levels - ELISAs were performed as described elsewhere (Paranhos-Silva et al. 1996). Microtitre plate (Corning Laboratory Science Co, NY, USA) wells were coated overnight at $4^{\circ} \mathrm{C}$ with $20 \mu \mathrm{g} \cdot \mathrm{mL}^{-1}$ (protein content) of Leishmania stationary-phase promastigote lysate or $0.5 \mu \mathrm{g} . \mathrm{mL}^{-1}$ of Leishmania recombinant protein in $100 \mu \mathrm{L}$ volumes of $0.1 \mathrm{M}$ carbonate buffer ( $\mathrm{pH}$ 9.6). The wells were washed three times with PBS containing $0.05 \%$ Tween 20 (Sigma Aldrich, St. Louis, MO, USA) and blocked with PBS containing 5\% dried skim milk for $1 \mathrm{~h}$ at $37^{\circ} \mathrm{C}$. After three washing procedures, the wells were incubated with $100 \mu \mathrm{L}$ of $1 / 400$ dilutions of test sera in PBS containing 3\% (dry w/v) skim milk and $0.05 \%$ Tween 20 for $1 \mathrm{~h}$ at $37^{\circ} \mathrm{C}$. The wells were washed again as before and $100-\mu \mathrm{L}$ volumes of an anti-dog IgGperoxidase conjugate (Sigma Aldrich, St. Louis, MO, USA), diluted at $1 / 2,000$, were added and incubated for $1 \mathrm{~h}$ at $37^{\circ} \mathrm{C}$. The wells were then washed again before the addition of $0.4 \mu \mathrm{L} \cdot \mathrm{mL}^{-1}$ of $30 \%$ hydrogen peroxide and 0.4 mg.mL ${ }^{-1}$ o-phenylenediamine (Sigma Aldrich, St. Louis, MO, USA) in $0.05 \mathrm{M}$ phosphate-citrate buffer, $\mathrm{pH}$ 5.0. After $20 \mathrm{~min}$, the reaction was stopped by the addition of $25 \mu \mathrm{L}$ of $2 \mathrm{~N}$ sulphuric acid and the optical density (OD) for 492-nm wave-length light was determined using a microtitre reader. Positive control sera from dogs with parasitologically proven infections and negative control sera from dogs with negative spleen cultures taken from a leishmaniasis non-endemic area were included in all plates. ODs above the cut-off were considered positive. To calculate the cut-off, the mean OD and the standard deviation (SD) of the mean were calculated based on sera from 53 dogs taken from Leishmaniafree areas. Then the obtained SD value was divided by the mean $\mathrm{OD}$. This provided the $\mathrm{SD} /$ mean ratio of the 53 negative controls. The cut-off value was different for each ELISA plate (correcting for the intrinsic interassay variations found in any enzymatic-based assay) and corresponded to the mean OD obtained with three negative control sera included in each ELISA plate plus two times the product of the mean OD of the three negative control sera and the $\mathrm{SD} /$ mean ratio of the 53 negative controls (Paranhos-Silva et al. 1996).

Lymphocyte proliferation assay - PBMCs were isolated by centrifugation of blood and diluted with ster- ile Hanks' balanced salt solution (Gibco-Invitrogen, Carlsbad, CA, USA) at a 1:1 (v/v) ratio with Histopaque1077 (Sigma Aldrich, St. Louis, MO, USA) solution. Purified PBMCs were washed three times at $4^{\circ} \mathrm{C}$ with RPMI medium and viable cells were adjusted to $2 \times 10^{6}$ in RPMI supplemented with $10 \%$ heat-inactivated FBS, $50 \mu \mathrm{g} . \mathrm{mL}-1$ gentamicin and $2 \mathrm{mM}$ L-glutamine (complete medium). Two hundred microlitres containing $2 \mathrm{x}$ $10^{5}$ cells was then cultured in complete medium either in the presence of $4 \mu \mathrm{g} . \mathrm{mL}^{-1}$ concanavalin A (Con A) (Sigma Aldrich, St. Louis, MO, USA) for three days or with $20 \mu \mathrm{g} \cdot \mathrm{mL}^{-1}$ (protein content) Leishmania lysate, $0.5 \mu \mathrm{g} . \mathrm{mL}^{-1} \mathrm{Lcil}$ or $16 \mu \mathrm{g} . \mathrm{mL}^{-1} \mathrm{Lci} 2$, for five days. These antigen and mitogen concentrations were found to be optimal in previous assays utilizing PBMCs of naturally infected dogs. All cultures were carried out in flat-bottomed microtitre plates (Corning Incorporated, Corning, NY, USA) in triplicate in a $100 \%$ humidified atmosphere with $5 \% \mathrm{CO}_{2}$ at $37^{\circ} \mathrm{C}$. Cells were pulsed during the last $18 \mathrm{~h}$ of culture with $1 \mu \mathrm{Ci}$ of $\left[{ }^{3} \mathrm{H}\right]$ thymidine (GE Healthcare UK Ltd, Little Chalfont, England) and harvested onto glass fibre filters utilising a cell harvester. Radioactivity uptake was measured in a liquid scintillation beta counter (Matrix 9600 Direct Beta Counter; Packard). Proliferative responses were expressed as a stimulation index (SI), which was calculated by dividing the mean counts of stimulated cultures by the mean counts of non-stimulated cultures. Stimulation indices equal to or higher than 2.5 were considered to be indicative of proliferation.

Quantification of interferon (IFN)- $\gamma$ levels - PBMCs were obtained as described above. Isolated PBMCs $\left(10^{7}\right.$ cells $\left./ \mathrm{mL}\right)$ were resuspended in complete RPMI medium and then plated onto wells of 6-well tissue culture plates (Costar Corning Inc, USA). Cells were incubated with $20 \mu \mathrm{g} \cdot \mathrm{mL}^{-1} \mathrm{~L}$. infantum lysate, $10 \mu \mathrm{g} \cdot \mathrm{mL}^{-1}$ of Con A (positive control) or medium alone (negative control) at $37^{\circ} \mathrm{C}$ with $5 \% \mathrm{CO}_{2}$. Supernatants were collected from the cultures at $48 \mathrm{~h}$ and stored at $-20^{\circ} \mathrm{C}$ until use. PBMCs from dogs that were injected with saline (2 animals) or with a mixture of the Lcil and Lci2 recombinant antigens (5 animals) were used as controls. IFN- $\gamma$ was measured by sandwich ELISA, according to the manufacturer's recommendations (R\&D Systems, Minneapolis, USA), using specific anti-dog IFN- $\gamma\left(1 \mu \mathrm{g} \cdot \mathrm{mL}^{-1}\right)$, biotinylated anti-dog IFN- $\gamma\left(100\right.$ ng.mL $\left.{ }^{-1}\right)$ and streptavidin conjugated to horseradish peroxidase (1:200). Absorbance values at $450 \mathrm{~nm}$ were read at $\mathrm{OD}_{450}$ in an automatic Microplate Reader EL 3311 (Boehring Mannheim, Germany). A standard curve for IFN- $\gamma$ was performed in successive dilutions from 32 ng. $\mathrm{mL}^{-1}-.03125$ ng. $\mathrm{mL}^{-1}$ of recombinant canine IFN- $\gamma$. Data are expressed in nanograms per millilitre.

Delayed-type hypersensitivity reaction - The skin test was performed as described previously (ParanhosSilva et al. 2001) using freeze-thawed, lysed L. infantum promastigotes diluted in sterile saline as the antigen. Dogs were injected intradermally at different sites of the abdomen with the following: (i) $100 \mu \mathrm{L}$ of lysate containing $250 \mu \mathrm{g}$ of protein, (ii) different concentrations of purified Lci1 $\left(12.5,25\right.$ and $\left.50 \mu \mathrm{g} \cdot \mathrm{mL}^{-1}\right)$ and Lci2 (25, 50 and $100 \mu \mathrm{g} \cdot \mathrm{mL}^{-1}$ ) recombinant proteins or (iii) saline 
alone. Intradermal indurations were measured $48 \mathrm{~h}$ and $72 \mathrm{~h}$ after injections. Reactions showing a diameter equal or larger than $5 \mathrm{~mm}$ were considered positive.

Statistical analyses - Results from measurements between two groups of dogs were statistically compared using the Mann-Whitney non-parametric U test. The statistical significance of the observed differences between three or more groups was determined by the Kruskal-Wallis test and Dunn's test was used as a post test to determine the statistical significance between two groups. A $p$ value $\leq 0.05$ was considered significant.

\section{RESULTS}

Specific antibody responses against total or recombinant L. infantum antigens - All dogs exhibited relatively low (OD values below 0.4 in the ELISA) but significantly $(\mathrm{p}<0.05)$ increased levels of anti- $L$. infantum IgG activity after two injections of promastigote lysate (Table I). Six weeks after the subcutaneous inoculation of virulent promastigotes, the antibody levels either remained constant (dogs 3 and 4$)$ or increased $(\operatorname{dogs} 1$ and 2) (Table I). A large and statistically significant (p $<0.05$ ) increase in anti- $L$. infantum antibody levels was observed 45 weeks after infection compared to levels observed before immunization and at three weeks after the intradermal injection of Leishmania lysate. Reactivity of the serum antibodies against the Lcil recombinant protein was observed in two animals (dogs 2 and 3) 45 weeks after viable promastigote inoculation. None of the animals had detectable serum antibodies against the Lci2 protein during the follow-up period (data not shown). Sera from the control group had no detectable anti-Leishmania antibodies (Table I).

Lymphoproliferative response and IFN- $\gamma$ production - Proliferative responses to crude Leishmania antigens were not observed after two subcutaneous injections of L. infantum lysate (Fig. 1A). Responses were observed only after inoculation of live promastigotes and were considerably higher after 45 weeks than after six weeks of infection in three of the four dogs (Fig. 1A). After 45 weeks (10.5 months) of infection, all animals responded to Lcil, while two of the four dogs (animals 3 and 4) responded to Lci2 protein, with a mean SI of 6.6 and 4.5, respectively (Fig. 1B). No PBMCs from animals of the control, non-immunized group had lymphoproliferative responses to the $L$. infantum lysate or to the recombinant proteins (Fig. 1B). Seven years after immunization, PBMCs from the animals still proliferated in response to $L$. infantum lysate (Fig. 2A).

Four years after the immunization, Leishmania antigen-stimulated PBMCs from the immunized animals produced detectable levels of IFN- $\gamma$, which were significantly different from the levels produced by PBMCs from seven animals that were injected with either saline (2 animals) or with a mixture of two recombinant antigens (5 animals) (Fig. 2B). PBMCs from immunized animals still produced IFN- $\gamma$ in response to Leishmania antigen seven years after immunization (data not shown).

Delayed-type hypersensitivity to crude and recombinant Leishmania antigens - Forty-five weeks after immunization, all dogs from the infected group had positive skin test reactions at the site of injection of crude $L$. infantum antigens, varying from $10-30 \mathrm{~mm}$ at $48 \mathrm{~h}$ and from $7-26 \mathrm{~mm}$ at $72 \mathrm{~h}$ (Table II). Three immunized animals had larger reactions at $48 \mathrm{~h}$, while one dog had an increase of induration area after the next $24 \mathrm{~h}$ (Table II). Three of four dogs from the immunized group reacted to higher concentrations of Lcil and one responded to both Lcil and Lci2 (Table II). No positive reactions were detected in the three control dogs.

Clinical and parasitological evaluation - The presence of parasites in spleen aspirate cultures was initially observed in two of the four immunized animals (dogs 2 and 3) six months after promastigote inoculation. There-

TABLE I

IgG anti-Leishmania antibodies in the sera of animals immunized with Leishmania infantum (dogs 1-4) or non-immunized (dogs 5-7) against L. infantum lysate and the Lcil (an Hsp70 heat shock protein polypeptide segment) recombinant antigen

\begin{tabular}{|c|c|c|c|c|c|c|c|c|}
\hline \multirow[b]{2}{*}{ Dog } & \multicolumn{4}{|c|}{ IgG anti-Leishmania lysate } & \multicolumn{4}{|c|}{ IgG anti-Lcil recombinant protein } \\
\hline & $\begin{array}{c}\text { Before } \\
\text { immunization }\end{array}$ & $\begin{array}{l}\text { Three weeks } \\
\text { after last of two } \\
\text { lysate injections }\end{array}$ & $\begin{array}{l}\text { Six weeks } \\
\text { after } \\
\text { infection }\end{array}$ & $\begin{array}{l}\text { Forty-five } \\
\text { weeks after } \\
\text { infection }\end{array}$ & $\begin{array}{c}\text { Before } \\
\text { immunization }\end{array}$ & $\begin{array}{l}\text { Three weeks } \\
\text { after last of two } \\
\text { lysate injections }\end{array}$ & $\begin{array}{l}\text { Six weeks } \\
\text { after } \\
\text { infection }\end{array}$ & $\begin{array}{l}\text { Forty-five } \\
\text { weeks after } \\
\text { infection }\end{array}$ \\
\hline 1 & $0.033^{a}$ & $0.202^{b}$ & $0.495^{b}$ & $2.013^{b}$ & 0.120 & 0.086 & 0.117 & 0.130 \\
\hline 2 & 0.190 & 0.379 & 0.802 & 3.038 & 0.141 & 0.256 & 0.278 & 1.706 \\
\hline 3 & 0.198 & 0.446 & 0.541 & 3.584 & 0.199 & 0.226 & 0.397 & 0.772 \\
\hline 4 & 0.109 & 0.405 & 0.442 & 0.657 & 0.108 & 0.079 & 0.086 & 0.115 \\
\hline 5 & 0.155 & 0.032 & 0.174 & 0.128 & 0.131 & 0.109 & 0.096 & 0.124 \\
\hline 6 & 0.142 & 0.177 & 0.124 & 0.212 & 0.138 & 0.142 & 0.107 & 0.154 \\
\hline 7 & 0.102 & 0.110 & 0.088 & 0.040 & 0.076 & 0.101 & 0.089 & 0.106 \\
\hline
\end{tabular}

$a$ : mean optical density at $460 \mathrm{~nm}$ obtained by enzyme linked immunosorbent assay from duplicates of an 1:400 serum dilution; $b: \mathrm{p}<0.05$, Kruskal-Wallis test followed by Dunn's post test. All immunized animals in relation to results before immunization and the animals at 45 weeks post-infection in relation to three weeks after injection of Leishmania lysate. 

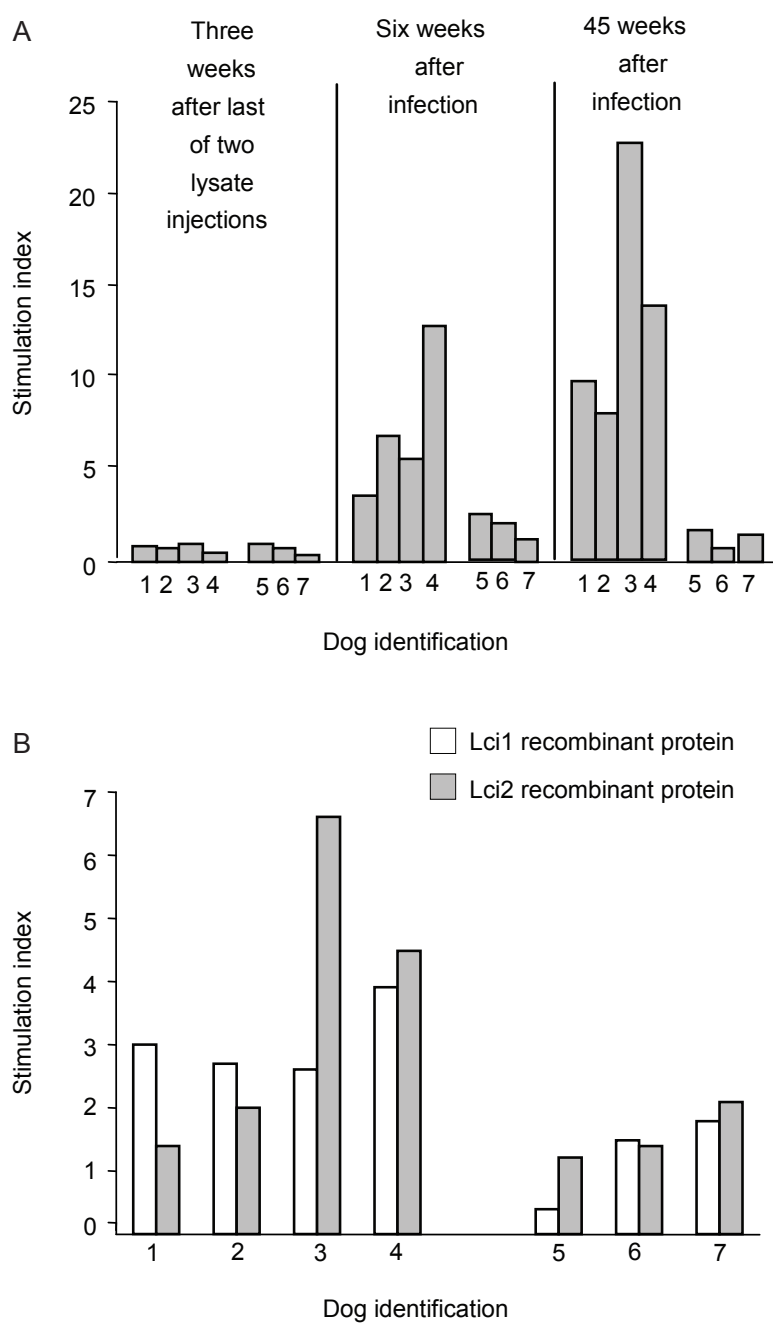

Fig. 1: lymphoproliferative response to Leishmania antigens in Leishmania infantum immunized dogs. A: proliferative response of peripheral blood mononuclear cells (PBMC) stimulated with L infantum promastigote lysate at different time points during the follow-up period; B: proliferative response of PBMC cultures stimulated with $L$. infantum Lci1 (an Hsp70 heat shock protein polypeptide segment) and Lci2 (a kinesin polypeptide segment) recombinant proteins after 45 weeks of infection. Each column represents the result obtained from an individual animal identified by the number under its base. Animals 1-4 were immunized with L. infantum as described in the Subjects, Materials and Methods; animals 5-7 were injected with saline only.

after, Leishmania parasites were isolated at least once from the spleen cultures of all infected dogs, despite the absence of clinical signs of VL, such as loss of weight, cachexia, alopecia and onychogryphosis. Dogs from the control group also remained healthy and all their spleen cultures were negative during the follow-up period.

\section{DISCUSSION}

A canine experimental model that can be used to study different immunological mechanisms involved in resistance and susceptibility to $L$. infantum infection or to test potential vaccine candidates should fulfil the following requirements: (i) provide Leishmania antigen-primed cells to test antigens for cellular immune
A

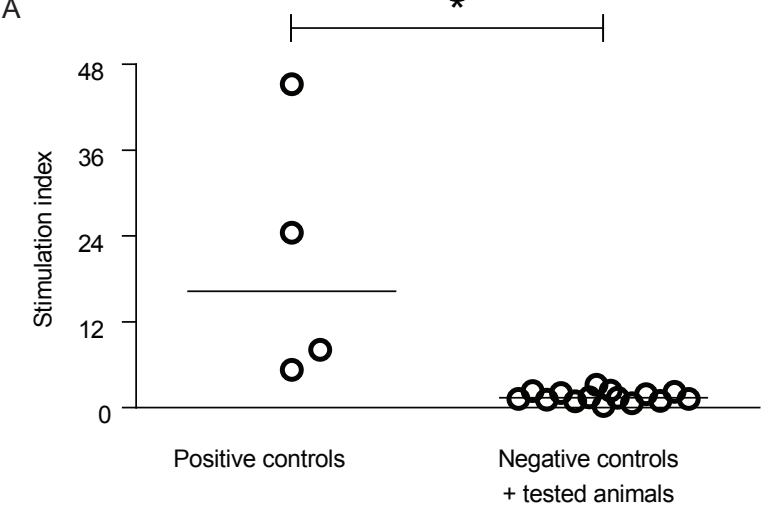

B
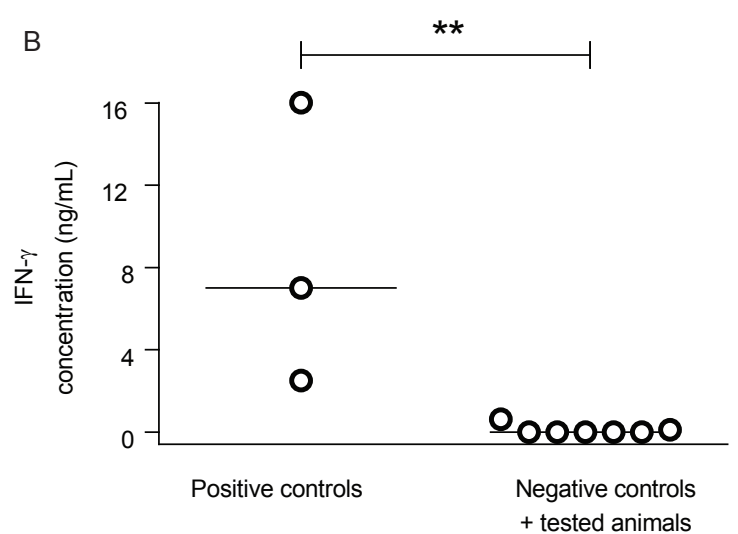

Fig. 2: lymphoproliferation and interferon- $\gamma($ IFN- $\gamma)$ production by peripheral blood mononuclear cells (PBMC) in response to Leishmania lysate in Leishmania infantum immunized dogs. A: proliferative response of PBMC, prepared from blood collected seven years after immunization, stimulated with $L$. infantum promastigote lysate; B: IFN- $\gamma$ levels in supernatants of cultures of PBMC (prepared from blood collected 4 years after immunization) stimulated with $L$. infantum promastigote lysate; negative controls + tested animals: animals that were injected with saline (5 animals in A and 2 animals in B) or with a mixture of the Lcil (an Hsp70 heat shock protein polypeptide segment) and Lci2 (a kinesin polypeptide segment) recombinant antigens (10 animals in A and 5 animals in B); positive controls: animals that were immunized with L. infantum as described in Subjects, Materials and Methods. Each symbol represents the result obtained from an individual animal. The horizontal lines correspond to the median value of each group of animals. *: $p<0.004 ;{ }^{* *}: \mathrm{p}<0.02$ (Mann-Whitney's U test).

responses in vitro, (ii) allow the assessment of delayed hypersensitivity reactions in vivo and (iii) be long-lasting. In this paper, we describe a protocol to develop an experimental model with these characteristics involving injections of a crude, easily obtained Leishmania lysate and the inoculation of live L. infantum amastigotes by the intradermal route. The animals treated with this protocol fulfil the requirements listed above based on the following results: (i) their PBMCs proliferated and/or produced IFN- $\gamma$ in response to Leishmania lysate or recombinant antigens, (ii) they had clearly positive delayed-type skin hypersensitivity reactions to Leishmania lysates and (iii) their immune systems remained sensitized to Leishmania antigens for several years (at least 7 years). These 


\section{TABLE II}

Skin reactions to a Leishmania infantum lysate and to the Lcil (an Hsp70 heat shock protein polypeptide segment) and Lci2 (a kinesin polypeptide segment) L. infantum recombinant antigens in animals immunized with L. infantum (dogs 1-4) or non-immunized (dogs 5-7), 45 weeks after infection with L. infantum

\begin{tabular}{|c|c|c|c|c|c|c|c|c|c|}
\hline \multirow[b]{2}{*}{ Dog } & \multirow[b]{2}{*}{$\begin{array}{l}\text { Time of } \\
\text { reaction reading }\end{array}$} & \multicolumn{8}{|c|}{ Diameter of skin indurations $(\mathrm{mm})$ after injection of } \\
\hline & & Saline & $\begin{array}{c}250 \mu \mathrm{g} \text { of } \\
\text { L. infantum lysate }\end{array}$ & $\begin{array}{l}12.5 \mu \mathrm{g} \\
\text { of Lcil }\end{array}$ & $\begin{array}{c}25 \mu \mathrm{g} \\
\text { of Lcil }\end{array}$ & $\begin{array}{c}50 \mu \mathrm{g} \\
\text { of Lcil }\end{array}$ & $\begin{array}{c}25 \mu \mathrm{g} \\
\text { of Lci2 }\end{array}$ & $\begin{array}{c}50 \mu \mathrm{g} \\
\text { of Lci2 }\end{array}$ & $\begin{array}{l}100 \mu g \\
\text { of Lci2 }\end{array}$ \\
\hline \multirow[t]{2}{*}{1} & $48^{a}$ & 0 & 10 & 0 & 5 & 7 & 0 & 0 & 0 \\
\hline & 72 & 0 & 7 & 0 & 8 & 7 & 0 & 0 & 0 \\
\hline \multirow[t]{2}{*}{2} & 48 & 0 & 24 & 0 & 9 & 4 & 0 & 4 & 6 \\
\hline & 72 & 3 & 20 & 0 & 8 & 3 & 0 & 7 & 8 \\
\hline \multirow[t]{2}{*}{3} & 48 & 3 & 30 & 0 & 0 & 4 & 0 & 0 & 0 \\
\hline & 72 & 0 & 22 & 0 & 0 & 10 & 0 & 0 & 0 \\
\hline \multirow[t]{2}{*}{4} & 48 & 0 & 22 & 0 & 0 & 0 & 0 & 0 & 0 \\
\hline & 72 & 0 & 26 & 0 & 0 & 0 & 0 & 0 & 0 \\
\hline \multirow[t]{2}{*}{5} & 48 & 2 & 4 & 0 & 0 & 0 & 0 & 0 & 4 \\
\hline & 72 & 0 & 0 & 0 & 0 & 0 & 0 & 0 & 4 \\
\hline \multirow[t]{2}{*}{6} & 48 & 0 & 3 & 0 & 0 & 0 & 0 & 0 & 3 \\
\hline & 72 & 0 & 0 & 0 & 0 & 0 & 0 & 0 & 0 \\
\hline \multirow[t]{2}{*}{7} & 48 & 0 & 0 & 0 & 0 & 0 & 0 & 0 & 0 \\
\hline & 72 & 0 & 0 & 0 & 0 & 0 & 0 & 0 & 0 \\
\hline
\end{tabular}

$a$ : hours after intradermal injection of dogs with $100 \mu \mathrm{L}$ of antigens or saline at different sites of the abdomen.

results confirm previous reports that indicated that the inoculation of dogs with $L$. infantum by the intradermal route induces long pre-patent periods and stimulates cell-mediated immune responses (Killick-Kendrick et al. 1994, Santos-Gomes et al. 2000, Leandro et al. 2001, Paranhos-Silva et al. 2003, Travi et al. 2009), although the follow-up periods mentioned in these reports are not as long as those in the present work.

In this study, the elicitation of strong cellular and humoral immune responses was clearly not associated with the injection of promastigote lysate: three weeks after the second lysate injection, the cellular immune response was undetectable in a lymphoproliferative assay and only low levels of anti- $L$. infantum antibodies were produced by the four animals. This scenario completely changed after the inoculation of $10^{8}$ viable promastigotes; the dogs developed increased cellular immune responses that persisted for at least seven years. These persistent immune responses likely reflect a long-lasting asymptomatic infection, as suggested by the transient detection of Leishmania amastigotes in spleen cultures. Thus, the increase in antibody production, the elicitation of lymphoproliferative response and the in vitro IFN- $\gamma$ production of antigen-stimulated PBMCs suggests that parasite-host interactions during the course of subclinical infection favours the triggering of both cellular and humoral anti-Leishmania immune responses in dogs. Moreover, the delayed skin hypersensitivity reaction found in the present work, together with the production of IFN- $\gamma$, is indicative of a Th1-type immune response (Dos-Santos et al. 2008).

It is possible that the dogs in the present study were found to remain consistently healthy after infection with stationary-phase promastigotes because of the previous injections of promastigote extract. The experimental infection of dogs with Leishmania produces inconsistent results with regards to the development of disease and the establishment of sub-clinical infection (Abranches et al. 1991, Nieto et al. 1999, Rhalem et al. 1999, Campino et al. 2000, Santos-Gomes et al. 2000, Leandro et al. 2001, Paranhos-Silva et al. 2003, Chamizo et al. 2005, Rodríguez-Cortés et al. 2007a, Carrillo et al. 2008).

This lack of consistency and reproducibility may be due to various factors, such as the route of inoculation, the size of the inoculum, the developmental stage of the parasite and the dog breed (reviewed by Moreno \& Alvar 2002). Indeed, the genetic background of the dog may be an important factor in the outcome of experimental infection (Solano-Gallego et al. 2000, Dantas-Torres 2007). In Brazil, it may be more appropriate to use mixed-breed dogs in experimental models to more accurately represent the genetic diversity of the dog population in Leishmania-endemic areas. In the experiments described herein, mongrel dogs, similar to the ones found inhabiting the Brazilian Bahia state endemic areas, were used. A desirable canine model for the screening of antigens with immune-protective properties through the assessment of their reactivity with products of the immune response would include healthy animals that have cellular immune responses to Leishmania antigens (diseaseresistant dogs), as was achieved in the present work. Of course, the experimental canine model reported here would not be appropriate for the study of pathological and/or immunological features of canine VL. The observation that the PBMCs from immunized dogs proliferated when incubated in vitro with the Lcil $(4 \mathrm{dogs})$ and the Lci2 (2 dogs) recombinant antigens and that the dogs 
had a delayed-type skin response to the Lcil (3 dogs) and the Lci2 $(1 \mathrm{dog})$ recombinant antigens indicates that the dog model described herein can be useful in attempts to identify antigens associated with immunity in resistant dogs. The fact that some dogs responded to the recombinant antigens and some did not is not surprising, given the heterogeneity of the immune response to Leishmania antigens in different dogs (Teixeira et al. 2007).

The availability of these immunized dogs that are apparently protected against the development of disease, as demonstrated by the lack of clinical symptoms and the presence of in vitro lymphoproliferative and delayedtype hypersensitivity responses to leishmanial antigens, provides a long-term source of Leishmania-sensitised animals for different experiments. Indeed, they have been previously used to show that subclinical infection with $L$. infantum in different animal species, including dogs, is an effective protocol to produce humoral immune responses against $L$. infantum amastigotes (Fróes et al. 2004). Additionally, supernatants from antigenstimulated PBMCs from these dogs could stimulate macrophages from healthy animals to control in vitro infection by L. infantum (Rodrigues et al. 2007).

The present study does not, however, exclude a possible suppressive or enhancing role for the initial injections of parasite lysate on the immune response, which could have subsequently been elicited or greatly stimulated by the infection. To investigate this possibility, a group of infected, non-immunized animals would have to be included in a study such as the one reported herein. Both ethical and financial aspects should be considered before carrying out this proposed study because the model reported herein involving two subcutaneous injections of easily obtained Leishmania lysate, followed by the inoculation of dogs with live promastigotes by the subcutaneous route, seems to induce a sustained cellular immune response, leading to an asymptomatic infection. The model could therefore be useful for both the selection and immunobiological studies of immunogenic Leishmania antigens, providing a useful source of responder animals with which to assess the potential of antigens as targets of cellular and humoral immune reactions and serving as a positive control for L. infantumspecific cellular immune responses in initial trials of canine vaccine candidates.

\section{REFERENCES}

Abranches P, Santos-Gomes G, Rachamim N, Campino L, Schnur LF, Jaffe CL 1991. An experimental model for canine visceral leishmaniasis. Parasite Immunol 13: 537-550.

Alvar J, Aparicio P, Aseffa A, Den Boer M, Cañavate C, Dedet JP, Gradoni L, Ter Horst R, López-Vélez R, Moreno J 2008. The relationship between leishmaniasis and AIDS: the second 10 years. Clin Microbiol Rev 21: 334-359.

Araújo MS, de Andrade RA, Sathler-Avelar R, Teixeira-Carvalho A, Andrade MC, Vianna LR, Mayrink W, Reis AB, Malaquias LC, Mello MN, Martins-Filho OA 2009. T-cell-derived cytokines, nitric oxide production by peripheral blood monocytes and seric anti-Leishmania (Leishmania) chagasi IgG subclass patterns following immunization against canine visceral leishmaniasis using Leishvaccine and Leishmune. Vaccine 27: 1008-1017.
Babu KR, Swaminathan S, Marten S, Khanna N, Rinas U 2000. Production of interferon-alpha in high cell density cultures of recombinant Escherichia coli and its single step purification from refolded inclusion body proteins. Appl Microbiol Biotechnol 53: 655-660.

Barsov EV 2009. Selective immortalization of tumor-specific T cells to establish long-term T-cell lines maintaining primary cell characteristics. Methods Mol Biol 511: 143-158.

Bartelt RR, Cruz-Orcutt N, Collins M, Houtman JC 2009. Comparison of $\mathrm{T}$ cell receptor-induced proximal signaling and downstream functions in immortalized and primary $\mathrm{T}$ cells. PLoS One 4: e5430.

Borja-Cabrera GP, Correia Pontes NN, da Silva VO, Paraguai de Souza E, Santos WR, Gomes EM, Luz KG, Palatnik M, Palatnik de Sousa CB 2002. Long lasting protection against canine kala-azar using the FML-QuilA saponin vaccine in an endemic area of Brazil (São Gonçalo do Amarante, RN). Vaccine 20: 3277-3284.

Borja-Cabrera GP, Santos FN, Bauer FS, Parra LE, Menz I, Morgado AA, Soares IS, Batista LM, Palatnik-de-Sousa CB 2008. Immunogenicity assay of the Leishmune vaccine against canine visceral leishmaniasis in Brazil. Vaccine 26: 4991-4997.

Borja-Cabrera GP, Santos FN, Santos FB, Trivellato FA, Kawasaki JK, Costa AC, Castro T, Nogueira FS, Moreira MA, Luvizotto MC, Palatnik M, Palatnik-de-Sousa CB 2010. Immunotherapy with the saponin enriched-Leishmune vaccine versus immunochemotherapy in dogs with natural canine visceral leishmaniasis. Vaccine 28: 597-603.

Bourdoiseau G, Hugnet C, Gonçalves RB, Vézilier F, Petit-Didier E, Papierok G, Lemesre JL 2009. Effective humoral and cellular immunoprotective responses in Li ESAp-MDP vaccinated protected dogs. Vet Immunol Immunopathol 128: 71-78.

Cabral M, O’Grady J, Alexander J 1992. Demonstration of Leishmania specific cell mediated and humoral immunity in asymptomatic dogs. Parasite Immunol 14: 531-539.

Campino L, Santos-Gomes G, Riça Capela MJ, Cortes S, Abranches P 2000. Infectivity of promastigotes and amastigotes of Leishmania infantum in a canine model for leishmaniosis. Vet Parasitol 92: 269-275.

Carrillo E, Crusat M, Nieto J, Chicharro C, Thomas M del C, Martínez E, Valladares B, Cañavate C, Requena JM, López MC, Alvar J, Moreno J 2008. Immunogenicity of HSP-70, KMP-11 and PFR-2 leishmanial antigens in the experimental model of canine visceral leishmaniasis. Vaccine 26: 1902-1911.

Cerbino Neto J, Werneck GL, Costa CH 2009. Factors associated with the incidence of urban visceral leishmaniasis: an ecological study in Teresina, Piauí state, Brazil. Cad Saude Publica 25: 1543-1551.

Chamizo C, Moreno J, Alvar J 2005. Semi-quantitative analysis of cytokine expression in asymptomatic canine leishmaniasis. Vet Immunol Immunopathol 103: 67-75.

Costa CH, Vieira JB 2001. Changes in the control program of visceral leishmaniasis in Brazil. Rev Soc Bras Med Trop 34: 223-228.

Dantas-Torres F 2007. The role of dogs as reservoirs of Leishmania parasites with emphasis on Leishmania (Leishmania) infantum and Leishmania (Viannia) braziliensis. Vet Parasitol 149: 139-146.

de Lima VM, Ikeda FA, Rossi CN, Feitosa MM, Vasconcelos RO, Nunes CM, Goto H 2010. Diminished $\mathrm{CD}^{+} / \mathrm{CD} 25^{+} \mathrm{T}$ cell and increased IFN-gamma levels occur in dogs vaccinated with Leishmune in an endemic area for visceral leishmaniasis. Vet Immunol Immunopathol 135: 296-302.

Desjeux P 2002. Urbanization: an increasing risk factor for leishmaniasis. World Health Organization. Wkly Epidemiol Rec 44: 365-372.

Dos-Santos WL, Jesus EE, Paranhos-Silva M, Pereira AM, Santos JC, Baleeiro CO, Nascimento EG, Moreira ED, Oliveira GG, Pontes- 
de-Carvalho LC 2008. Associations among immunological, parasitological and clinical parameters in canine visceral leishmaniasis: emaciation, spleen parasitism, specific antibodies and leishmanin skin test reaction. Vet Immunol Immunopathol 123: 251-259.

Dye C 1996. The logic of visceral leishmaniasis control. Am J Trop Med Hyg 55: 125-130.

Fróes AM, dos Santos CV, Penha-Filho ML, Teixeira MC, Correa Silva TM, Oliveira GG, dos Santos WL, Pontes-de-Carvalho LC, Alcântara-Neves NM 2004. Sub-clinical infection as an effective protocol for obtaining anti-Leishmania chagasi amastigote antibodies of different animal species. Vet Immunol Immunopathol 99: 135-141.

Fujiwara RT, Vale AM, França da Silva JC, da Costa RT, Quetz J da S, Martins Filho OA, Reis AB, Corrêa Oliveira R, Machado-Coelho GL, Bueno LL, Bethony JM, Frank G, Nascimento E, Genaro O, Mayrink W, Reed S, Campos-Neto A 2005. Immunogenicity in dogs of three recombinant antigens (TSA, LeIF and LmSTI1) potential vaccine candidates for canine visceral leishmaniasis. Vet Res 36: 827-838.

Jedrzejas MJ, Mewbourne RB, Chantalat L, McPherson DT 1998. Expression and purification of Streptococcus pneumoniae hyaluronate lyase from Escherichia coli. Protein Expr Purif 13: 83-89.

Killick-Kendrick R, Killick-Kendrick M, Pinelli E, Del Real G, Molina R, Vitutia MM, Cañavate MC, Nieto J 1994. A laboratory model of canine leishmaniasis: the inoculation of dogs with Leishmania infantum promastigotes from midguts of experimentally infected phlebotomine sandflies. Parasite 1: 311-318.

Laemmli UK 1970. Cleavage of structural proteins during the assembly of the head of the bacteriophage T4. Nature 227: 680-685.

Leandro C, Santos-Gomes GM, Campino L, Romão P, Cortes S, Rolão N, Gomes-Pereira S, Riça Capela MJ, Abranches P 2001. Cell mediated immunity and specific $\mathrm{IgG} 1$ and $\mathrm{IgG} 2$ antibody response in natural and experimental canine leishmaniosis. Vet Immunol Immunopathol 79: 273-284.

Lorenzen A, Kennedy SW 1993. A fluorescence-based protein assay for use with a microplate reader. Anal Biochem 214: 346-348.

Maroli M, Rossi L, Baldelli R, Capelli G, Ferroglio E, Genchi C, Gramiccia M, Mortarino M, Pietrobelli M, Gradoni L 2008. The northward spread of leishmaniasis in Italy: evidence from retrospective and ongoing studies on the canine reservoir and phlebotomine vectors. Trop Med Int Health 13: 256-264.

Maurício IL, Stothard JR, Miles MA 2000. The strange case of Leishmania chagasi. Parasitol Today 16: 188-189.

Mestre GL, Fontes CJ 2007. The spread of the visceral leishmaniasis epidemic in the state of Mato Grosso, 1998-2005. Rev Soc Bras Med Trop 40: 42-48.

Moreno J, Alvar J 2002. Canine leishmaniasis: epidemiological risk and the experimental model. Trends Parasitol 18: 399-405.

Moreno J, Nieto J, Masina S, Cañavate C, Cruz I, Chicharro C, Carrillo E, Napp S, Reymond C, Kaye PM, Smith DF, Fasel N, Alvar J 2007. Immunization with H1, HASPB1 and MML Leishmania proteins in a vaccine trial against experimental canine leishmaniasis. Vaccine 25: 5290-5300.

Nieto CG, García-Alonso M, Requena JM, Mirón C, Soto M, Alonso C, Navarrete I 1999. Analysis of the humoral immune response against total and recombinant antigens of Leishmania infantum: correlation with disease progression in canine experimental leishmaniasis. Vet Immunol Immunopathol 67: 117-130.

Paranhos-Silva M, Freitas LA, Santos WC, Grimaldi G Júnior, Pontesde-Carvalho LC, Oliveira-dos-Santos AJ 1996. A cross-sectional serodiagnostic survey of canine leishmaniasis due to Leishmania chagasi. Am J Trop Med Hyg 55: 39-44.
Paranhos-Silva M, Oliveira GG, Reis EA, de Menezes RM, Fernandes O, Sherlock I, Gomes RB, Pontes-de-Carvalho LC, dos-Santos WL 2003. A follow-up of Beagle dogs intradermally infected with Leishmania chagasi in the presence or absence of sand fly saliva. Vet Parasitol 114: 97-111.

Paranhos-Silva M, Pontes-de-Carvalho LC, de Sá Oliveira GG, Góes Nascimento E, dos-Santos WLC 2001. Skin reactions to thimerosal and Leishmania in dogs from a leishmaniasis endemic area: it is better to keep them apart. Mem Inst Oswaldo Cruz 96: 679-681.

Pinelli E, Killick-Kendrick R, Wagenaar J, Bernadina W, del Real G, Ruitenberg J 1994. Cellular and humoral immune responses in dogs experimentally and naturally infected with Leishmania infantum. Infect Immun 62: 229-235.

Rhalem A, Sahibi H, Guessous-Idrissi N, Lasri S, Natami A, Riyad M, Berrag B 1999. Immune response against Leishmania antigens in dogs naturally and experimentally infected with Leishmania infantum. Vet Parasitol 81: 173-184.

Rodrigues CA, Batista LF, Teixeira MC, Pereira AM, Santos PO, de Sá Oliveira GG, de Freitas LA, Veras PS 2007. Peripheral blood mononuclear cell supernatants from asymptomatic dogs immunized and experimentally challenged with Leishmania chagasi can stimulate canine macrophages to reduce infection in vitro. Vet Parasitol 143: 197-205.

Rodríguez-Cortés A, Ojeda A, López-Fuertes L, Timón M, Altet L, Solano-Gallego L, Sánchez-Robert E, Francino O, Alberola J 2007a. A long term experimental study of canine visceral leishmaniasis. Int J Parasitol 37: 683-693.

Rodríguez-Cortés A, Ojeda A, López-Fuertes L, Timón M, Altet L, Solano-Gallego L, Sánchez-Robert E, Francino O, Alberola J 2007b. Vaccination with plasmid DNA encoding KMPII, TRYP, LACK and GP63 does not protect dogs against Leishmania infantum experimental challenge. Vaccine 25: 7962-7971.

Santos POM 2007. Avaliação da resposta imune em cães após imunização com dois antígenos recombinantes de Leishmania chagasi/L. infantum em associação à interleucina 12 (IL-12) canina, MSc Thesis, Universidade Federal da Bahia, Salvador, 100 pp.

Santos-Gomes GM, Campino L, Abranches P 2000. Canine experimental infection: intradermal inoculation of Leishmania infantum promastigotes. Mem Inst Oswaldo Cruz 95: 193-198.

Solano-Gallego L, Llull J, Ramos G, Riera C, Arboix M, Alberola J, Ferrer L 2000. The Ibizian hound presents a predominantly cellular immune response against natural Leishmania infection. Vet Parasitol 90: 37-45.

Teixeira MC, Oliveira GG, Silvany MA, Alcântara-Neves NM, Soares MB, Ribeiro-Dos-Santos R, Jerônimo SM, Costa CH, dos-Santos WL, Eichinger D, Pontes-de-Carvalho L 2007. A strategy for identifying serodiagnostically relevant antigens of Leishmania or other pathogens in genetic libraries. Biologicals 35: 51-54.

Travi BL, Osorio EY, Saldarriaga OA, Cadena H, Tabares CJ, Peniche A, Lee S, Melby PC 2009. Clinical, parasitologic, and immunologic evolution in dogs experimentally infected with sand fly-derived Leishmania chagasi promastigotes. Am J Trop Med Hyg 81: 994-1003.

Travi BL, Tabares CJ, Cadena H, Ferro C, Osorio Y 2001. Canine visceral leishmaniasis in Colombia: relationship between clinical and parasitologic status and infectivity for sand flies. Am J Trop Med Hyg 64: 119-124.

Verçosa BL, Lemos CM, Mendonça IL, Silva SM, de Carvalho SM, Goto H, Costa FA 2008. Transmission potential, skin inflammatory response and parasitism of symptomatic and asymptomatic dogs with visceral leishmaniasis. BMC Vet Res 4: 45. 